\title{
BMJ Open Minimum pupil in pupillary response to light and myopia affect disk halo size: a cross-sectional study
}

\author{
Feng Zhao, ${ }^{1,2}$ Tian Han, ${ }^{1,2}$ Xun Chen, ${ }^{1,2}$ Zhi Chen, ${ }^{1,2}$ Ke Zheng, ${ }^{1,2}$ Xiaoying Wang, ${ }^{1,2}$ \\ Xingtao Zhou ${ }^{1,2}$
}

To cite: Zhao F, Han T, Chen $X$, et al. Minimum pupil in pupillary response to light and myopia affect disk halo size: a crosssectional study. BMJ Open 2018;8:e019914. doi:10.1136/ bmjopen-2017-019914

- Prepublication history for this paper is available online. To view these files, please visit the journal online (http://dx.doi. org/10.1136/bmjopen-2017019914).

FZ and TH contributed equally.

Received 7 October 2017 Revised 1 February 2018 Accepted 2 February 2018
Check for updates

${ }^{1}$ Key Laboratory of Myopia Ministry of Health, Fudan University, Shanghai, China ${ }^{2}$ Department of Ophthalmology, Eye and ENT Hospital, Fudan University, Shanghai, China

Correspondence to Professor Xiaoying Wang; doctzhouxingtao@163.com and Dr Xingtao Zhou; doctzhouxingta0@163.com

\section{ABSTRACT}

Objectives To evaluate the relationship between pupillary response to light, myopia and disk halo size.

Design Cross-sectional study.

Setting Single refractive surgery centre.

Participants In this study, 197 right eyes of 197 patients between 20 and 35 years of age were evaluated for disk halo size and pupillary response to light with a vision monitor.

Primary and secondary outcome measures Halo radius, age, spherical equivalent (SE), axial length (AL), initial diameter, amplitude of contraction, latency of contraction, duration of contraction, velocity of contraction, latency of dilation, duration of dilation, velocity of dilation, maximum pupil, minimum pupil, average pupil and dark pupil. Results Significant associations were found between disk halo size and $S E(r=-0.219, P=0.002), A L(r=0.152$, $\mathrm{P}=0.033)$ and minimum pupil $(r=0.149, \mathrm{P}=0.037)$. There were no associations between disk halo size and initial diameter, amplitude of contraction, latency of contraction, duration of contraction, velocity of contraction, latency of dilation, duration of dilation, velocity of dilation, maximum pupil, average pupil, dark pupil and age $(P>0.05)$. A significant difference in disk halo size was detected between the low-moderate and high myopia $(\mathrm{SE}<-6$ D) groups $(\mathrm{P}=0.002)$ and between the small and large (minimum pupil $\geq 4 \mathrm{~mm}$ ) minimum pupil size groups ( $\mathrm{P}=0.014)$.

Conclusions Patients with a high SE and large minimum pupil size (minimum pupil $\geq 4 \mathrm{~mm}$ ) suffered more disability glare than those with a low SE and small minimum pupil size.

\section{INTRODUCTION}

Light from a bright light source entering the retina is diffused by the various optical elements of the eye. The diffused light creates a veil over the back of the retina which can lead to a loss in contrast and details of an object. The phenomenon is referred to as disability glare, and the veil is known as disk halos. ${ }^{12}$ The phenomenon usually occurs in patients with unclean spectacles, ${ }^{3}$ contact lenses, ${ }^{3}$ cataract ${ }^{4}$ and eyes that underwent refractive surgeries, ${ }^{5-7}$ keratoplasty ${ }^{8}$ or intraocular lenses implantation. ${ }^{9}$ Disability glare

\section{Strengths and limitations of this study}

This study involved a relatively comprehensive myopia spectrum (ranging from -1.50 to -18.00 ) and parameters of pupillary responses to light in detail.

- The inclusion age range was set to 20-35 years to avoid the relationship betweeen age and pupillary response to light as well as disk halo size.

- It would have been better to take contrast sensitivity into consideration.

- Subjective evaluation in the form of a questionnaire could have been used to further support the evidence.

impacts daily life, especially driving at night. Moreover, with ophthalmic surgeons increasingly emphasising visual quality, especially regarding therapies for myopia, cataract and so on, disability glare is worth attention.

Although some methods have been developed to measure disability glare, subject factors have a great influence on the results and might induce confusing outcomes. ${ }^{3} 69$ In this study, we used a new vision monitor (MonCv3; Metrovision, Pérenchies, France), which is able to measure disk halo size objectively and accurately with good repeatability. ${ }^{10}$

Considering that the influence of age on glare has been well studied, ${ }^{10}{ }^{11}$ we focused on the role of pupillary response to light and myopia in this study.

\section{PATIENTS AND METHODS}

This study followed the tenets of the Declaration of Helsinki. Informed consent was obtained from all participants.

\section{Subjects}

Patients undergoing a routine preoperative examination prior to myopic refractive surgery at the Refractive Surgery Center of the Department of Ophthalmology, Eye and ENT Hospital of Fudan University between December 2015 and June 2016 were enrolled 
in this cross-sectional study. Inclusion criteria included an age of 20 to 35 years, myopia and a corrected distance visual acuity of $20 / 20$ or better. Patients with systemic diseases, a history of ocular surgery or trauma or a history of ocular disease other than myopia or astigmatism were excluded.

\section{Measurements}

Disk halo size and pupillary response to light was measured using the vision monitor operated by an experienced technician. As described in previous studies,${ }^{10}$ patients with a refractive error fully corrected by a lens were seated $2.5 \mathrm{~m}$ in front of the machine and covered the left eye after $5 \mathrm{~min}$ of darkness adaptation. The light source on the right was used to test the right eye with a luminance of $5 \mathrm{~cd} / \mathrm{m}^{2}$, since this luminance is suitable for normal individuals. ${ }^{10}$ Patients were told to not look directly at the light source to avoid a retinal after image and were encouraged to read the letters farthest from the light source and move inward. There were three radial lines of 10 letters appearing from the periphery towards the light source on the screen: 10 letters forming 10 rings at intervals of $30 \mathrm{~min}$ of arc. The average distance of the nearest letter to the light source in each line was collected, and then the visual angle formed by the radius of the halo was calculated in minutes of arc. The score of each correct letter was calculated as 10.

As described by Martucci et $a l,{ }^{12}$ to decrease the influence of circadian ${ }^{13}$ on the pupillary response to light, measurements were taken between 09:00 and 12:00 after 5 min of darkness adaptation. White light was flashed in both eyes for a duration of $90 \mathrm{~s}$ (200 ms of stimulation on time, $3300 \mathrm{~ms}$ of stimulation off time, $100 \mathrm{~cd} / \mathrm{m}^{2}$ of total luminance and $20 \mathrm{~cd} \cdot \mathrm{s} / \mathrm{m}^{2}$ of total intensity). The dynamic responses to the light flashes were automatically recorded by a high-resolution near-infrared sensor at a speed of 30 images per second. Then the images were provided by the professional analysis software with an accuracy of $0.1 \mathrm{~mm}$. The following parameters were collected: initial diameter, amplitude of contraction, latency of contraction, duration of contraction, velocity of contraction, latency of dilation, duration of dilation, velocity of dilation, maximum pupil, minimum pupil and average pupil.

Dark pupil size was measured to the nearest tenth of a millimetre using a pupilometer (NIDEK ARK-510A) under mesopic conditions.

Axial length (AL) was measured with partial coherence interferometry (IOL Master, Carl Zeiss, Germany) five times and automatically averaged.

\section{Statistical analysis}

All statistical analysis was performed using SPSS V.22. The data of the right eye of each patients were chosen. The Spearman's test was used to examine the relationship between factors. The Mann-Whitney test was used to assess the difference in disk halo size between subgroups groups. For all tests, a $\mathrm{P}<0.05$ was defined as statistically significant.

\begin{tabular}{|c|c|c|c|c|}
\hline Parameters & Mean & SD & Minimum & Maximum \\
\hline Age (years) & 26.31 & 4.83 & 20 & 35 \\
\hline Sphere (D) & -5.83 & 2.71 & -17.50 & -1.00 \\
\hline Cylinder (D) & -0.95 & 0.78 & -4.25 & 0.00 \\
\hline SE (D) & -6.31 & 2.83 & -18.00 & -1.50 \\
\hline Axial length & 26.16 & 1.19 & 23.40 & 31.64 \\
\hline Dark pupil (mm) & 6.99 & 0.68 & 5.00 & 8.40 \\
\hline Initial diameter (mm) & 5.29 & 0.65 & 3.80 & 7.20 \\
\hline $\begin{array}{l}\text { Amplitude of } \\
\text { contraction }(\mathrm{mm})\end{array}$ & 1.97 & 1.47 & 0.90 & 22.00 \\
\hline $\begin{array}{l}\text { Latency of } \\
\text { contraction (ms) }\end{array}$ & 238.66 & 70.30 & 15.00 & 338.00 \\
\hline $\begin{array}{l}\text { Duration of } \\
\text { contraction (ms) }\end{array}$ & 642.82 & 91.27 & 451.00 & 1028.00 \\
\hline $\begin{array}{l}\text { Velocity of } \\
\text { contraction }(\mathrm{mm} / \mathrm{s})\end{array}$ & 5.92 & 0.96 & 3.25 & 8.40 \\
\hline $\begin{array}{l}\text { Latency of dilation } \\
\text { (ms) }\end{array}$ & 881.78 & 66.68 & 733.00 & 1132.00 \\
\hline $\begin{array}{l}\text { Duration of dilation } \\
\text { (ms) }\end{array}$ & 1573.19 & 91.23 & 1139.00 & 1767.00 \\
\hline $\begin{array}{l}\text { Velocity of dilation } \\
(\mathrm{mm} / \mathrm{s})\end{array}$ & 2.37 & 0.66 & 1.34 & 7.34 \\
\hline Maximum pupil (mm) & 5.79 & 0.67 & 4.10 & 7.90 \\
\hline Minimum pupil (mm) & 3.37 & 0.49 & 2.30 & 5.20 \\
\hline Average pupil (mm) & 4.75 & 0.57 & 3.40 & 6.40 \\
\hline Score & 64.13 & 19.54 & 10.00 & 96.70 \\
\hline $\begin{array}{l}\text { Halo radius (arc } \\
\text { minutes) }\end{array}$ & 157.36 & 56.73 & 60.00 & 330.00 \\
\hline
\end{tabular}

All measurements went uneventful.

D, dioptre; SE, spherical equivalent.

\section{RESULTS}

One hundred ninety-seven right eyes of 197 patients (65 male and 132 female) were enrolled in the study. The demographic characteristics are shown in table 1.

Table 2 shows a significant association between disk halo size and spherical equivalent ( $\mathrm{SE} ; \mathrm{r}=-0.219, \mathrm{P}=0.002), \mathrm{AL}$ $(\mathrm{r}=0.152, \mathrm{P}=0.033)$ and minimum pupil $(\mathrm{r}=0.149, \mathrm{P}=0.037)$ (figure 1) and a significant association between score and SE $(\mathrm{r}=0.218, \mathrm{P}=0.002)$, AL $(\mathrm{r}=-0.167, \mathrm{P}=0.019)$ and minimum pupil $(\mathrm{r}=-0.148, \mathrm{P}=0.038)$. There was no association between minimum pupil and $\mathrm{SE}(\mathrm{r}=0.105, \mathrm{P}=0.143)$ and $\mathrm{AL}(\mathrm{r}=0.007, \mathrm{P}=0.927)$. There was no association between disk halo size as well as score and initial diameter, amplitude of contraction, latency of contraction, duration of contraction, velocity of contraction, latency of dilation, duration of dilation, velocity of dilation, maximum pupil, average pupil, dark pupil and age $(\mathrm{P}>0.05)$ (table 2$)$.

Two subgroups were categorised according to SE values, with 110 eyes in the low-moderate myopia group ( $\mathrm{SE} \geq$ $-6 \mathrm{D})$ and 87 eyes in the high myopia group $(\mathrm{SE}<-6 \mathrm{D})$. A significant difference in disk halo size $(\mathrm{P}=0.002)$ and score $(\mathrm{P}=0.003)$ was detected between low-moderate and high myopia groups (table 3 ). 
Table 2 Correlation analysis between age, spherical equivalent refraction, pupil parameters and halo parameters

\begin{tabular}{|c|c|c|c|c|}
\hline \multirow[b]{2}{*}{ Variables } & \multicolumn{2}{|c|}{$\begin{array}{l}\text { Halo radius (arc } \\
\text { minutes) }\end{array}$} & \multirow{2}{*}{$\begin{array}{l}\text { Score } \\
r\end{array}$} & \multirow[b]{2}{*}{$\mathbf{P}$} \\
\hline & $\mathbf{r}$ & $\mathbf{P}$ & & \\
\hline Age (years) & 0.017 & 0.816 & -0.026 & 0.717 \\
\hline SE (D) & $-0.219^{* *}$ & 0.002 & $0.218^{* *}$ & 0.002 \\
\hline Axial length & $0.152^{*}$ & 0.033 & $-0.167^{*}$ & 0.019 \\
\hline Dark pupil (mm) & 0.071 & 0.320 & -0.070 & 0.325 \\
\hline Initial diameter (mm) & 0.103 & 0.149 & -0.090 & 0.208 \\
\hline $\begin{array}{l}\text { Amplitude of contraction } \\
(\mathrm{mm})\end{array}$ & -0.003 & 0.964 & 0.019 & 0.793 \\
\hline $\begin{array}{l}\text { Latency of contraction } \\
\text { (ms) }\end{array}$ & -0.048 & 0.506 & 0.066 & 0.358 \\
\hline $\begin{array}{l}\text { Duration of contraction } \\
\text { (ms) }\end{array}$ & 0.057 & 0.425 & -0.074 & 0.304 \\
\hline $\begin{array}{l}\text { Velocity of contraction } \\
(\mathrm{mm} / \mathrm{s})\end{array}$ & -0.010 & 0.890 & 0.025 & 0.726 \\
\hline Latency of dilation (ms) & 0.011 & 0.874 & -0.015 & 0.836 \\
\hline Duration of dilation (ms) & -0.024 & 0.734 & 0.047 & 0.512 \\
\hline Velocity of dilation $(\mathrm{mm} / \mathrm{s})$ & 0.075 & 0.292 & -0.079 & 0.272 \\
\hline Maximum pupil (mm) & 0.087 & 0.225 & -0.080 & 0.264 \\
\hline Minimum pupil (mm) & $0.149^{*}$ & 0.037 & $-0.148^{*}$ & 0.038 \\
\hline Average pupil (mm) & 0.124 & 0.082 & -0.120 & 0.092 \\
\hline
\end{tabular}

$\mathrm{D}$, dioptre; r, correlation coefficient; SE, spherical equivalent. *, $\mathrm{P}<$ $0.05 ;{ }^{* \star}, \mathrm{P}<0.01$.

Two subgroups were categorised according to minimum pupil values, with 173 eyes in the small minimum pupil group (minimum pupil $<4 \mathrm{~mm}$ ) and 24 eyes in the large minimum pupil group (minimum pupil $\geq 4 \mathrm{~mm}$ ). A significant difference in disk halo size $(\mathrm{P}=0.014)$ and score $(\mathrm{P}=0.011)$ was detected between the two groups (table 4$)$.

\section{DISCUSSION}

Disability glare is a common disturbance in daily life, and its factors have been a topic of interest since the 1920s. ${ }^{11}$ In this study, we investigated the role of myopia and pupillary response on disk halo size.

Because age has a relationship on both pupillary response to light and disk halo size, ${ }^{14} 15$ and patients between 20 and 50 years of age have similar disk halo sizes, ${ }^{10}$ the inclusion age range was set to $20-35$ years.

There was a significant association between disk halo size and SE. Moreover, disk halo size was significantly different between the low-moderate and high myopia groups. Thus, patients with high myopia are more likely to be disturbed by disk halo size than those with low myopia. There was a discrepancy between Cervino et $a \tilde{l}$ and our results. They studied 30 eyes with an SE between $-4.00 \mathrm{D}$ and $0 \mathrm{D}$ and found no relation between SE and luminous distortion index. This difference might be related to the range of myopia and sample size. In addition, it shows that a unified approach for measuring disability glare is important for clinical practice and
A

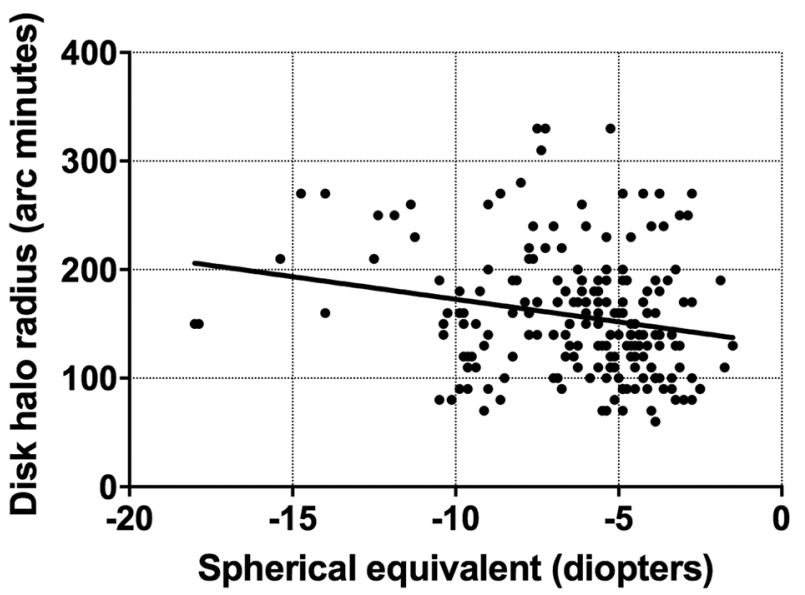

B
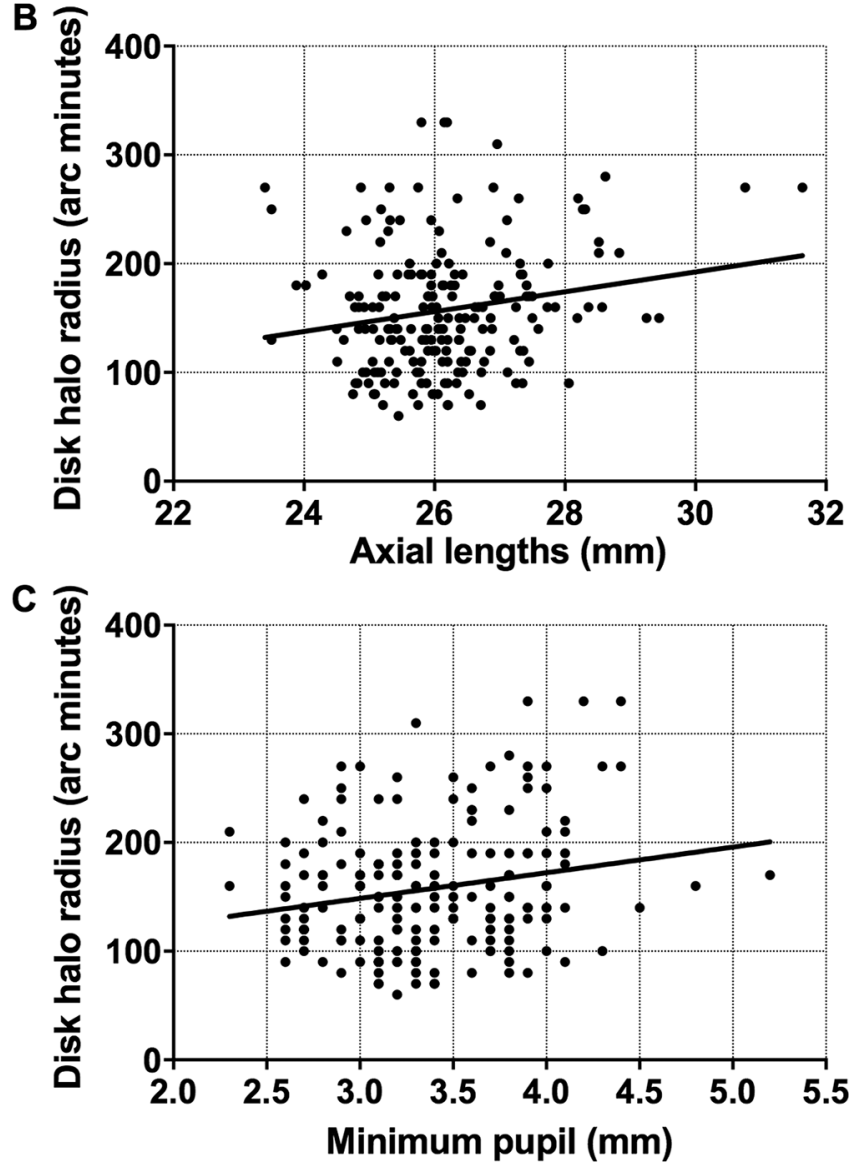

Figure 1 Scatter diagrams of spherical equivalents (A), axial length (B) and minimum pupil (C) against disk halo size, demonstrating significant correlation between spherical equivalent $(P=0.002)$, axial length ( $P=0.033)$, minimum pupil $(P=0.037)$ and disk halo size.

scientific research. One explanation for the relationship between disk halo size and SE is the optical quality. Individuals with a higher degree of myopia tend to have lower optical quality and greater intraocular scatter, which might cause a greater disk halo size. ${ }^{16}$ Moreover, the lens that was used in the test may have influenced the outcomes.

Similar to previous studies on other measurements of disability glare,,$^{71718}$ there was no relationship between 
Table 3 Halo parameters in different myopic groups

\begin{tabular}{|c|c|c|c|c|c|}
\hline & \multicolumn{2}{|c|}{$\begin{array}{l}\text { Low-moderate } \\
\text { myopia }(n=110)\end{array}$} & \multicolumn{2}{|c|}{$\begin{array}{l}\text { High myopia } \\
(\mathrm{n}=87)\end{array}$} & \\
\hline & Mean & SD & Mean & SD & \\
\hline SE (D) & -4.39 & 1.01 & -8.74 & 2.50 & $<0.001$ \\
\hline LogMAR CDVA & 0.06 & 0.03 & 0.05 & 0.04 & 0.078 \\
\hline Minimum pupil (mm) & 3.40 & 0.46 & 3.33 & 0.52 & 0.352 \\
\hline $\begin{array}{l}\text { Halo radius (arc } \\
\text { minutes) }\end{array}$ & 146.27 & 52.76 & 171.38 & 58.75 & 0.002 \\
\hline Score & 68.00 & 17.90 & 59.24 & 20.50 & 0.003 \\
\hline
\end{tabular}

CDVA, corrected distance visual acuity; D, dioptre; $\mathrm{SE}$, spherical equivalent.

disk halo size and dark pupil in this study. It is supposed that the phenomenon might be related to a pupillary response to light. We investigated the data on pupillary response to light and found a significant correlation between minimum pupil and disk halo size. There was no association between SE and minimum pupil. Furthermore, there was no association between disk halo size and initial diameter, amplitude of contraction, latency of contraction, duration of contraction, velocity of contraction, latency of dilation, duration of dilation, velocity of dilation, maximum pupil and average pupil. Moreover, eyes with a minimum pupil larger than $4 \mathrm{~mm}$ suffered from a greater disk halo size than those with a minimum pupil less than $4 \mathrm{~mm}$. One possible explanation might be that when light from a bright light source enters an eye that is otherwise in darkness, a pupil contraction occurs and the minimum pupil forms immediately in about $1 \mathrm{~s}$ (a total of contraction latency and duration). The potential in the retinal pigment epithelium (RPE) is a local potential, and the amplitude of the local potential increases with the amount of stimulation. Eyes with a larger minimum pupil receive more light and experience more light scattering. More RPEs receive the light stimulation, leading to a higher disk halo size. Thus, minimum pupil plays an important role with disk halo size.

In clinical practice, it is common that the severity of disability glare after refractive surgeries is not related to pupil size. ${ }^{718-21}$ For example, Schallhorn et $a l^{18}$ used questionnaires to investigate the subjective visual quality of 10944 eyes of 5563 young patients with myopia who

Table 4 Halo parameters in different minimum pupil groups

\begin{tabular}{|c|c|c|c|c|c|}
\hline & \multicolumn{2}{|c|}{$\begin{array}{l}\text { Low minimum } \\
\text { pupil }(n=173)\end{array}$} & \multicolumn{2}{|c|}{$\begin{array}{l}\text { High minimum } \\
\text { pupil }(n=24)\end{array}$} & \\
\hline & Mean & SD & Mean & SD & \\
\hline Minimum pupil (mm) & 3.26 & 0.39 & 4.20 & 0.30 & $<0.001$ \\
\hline SE (D) & -6.30 & 2.79 & -6.36 & 3.12 & 0.906 \\
\hline $\begin{array}{l}\text { Halo radius (arc } \\
\text { minutes) }\end{array}$ & 152.89 & 53.69 & 189.58 & 68.11 & 0.014 \\
\hline Score & 65.59 & 18.72 & 53.62 & 22.37 & 0.011 \\
\hline
\end{tabular}

D, dioptre; SE, spherical equivalent. underwent wavefront-guided LASIK (laser-assisted in situ keratomileusis) and found no correlation between dark pupil diameter and patient-reported outcomes. Our study might help to explain the phenomenon to some extent, since in those studies, the preoperative SE and minimum pupil was not taken into consideration. Patients with a high SE and large minimum pupil size experience disability glare preoperation, and subjectively measuring glare only at postoperation could lead to confusing outcomes. In addition, some patients might have both a large dark pupil size and a small minimum pupil size. Thus, it is important to investigate disability glare before and after ophthalmic surgeries when evaluating disability glare, especially if a subjective method of measurement, such as a questionnaire, is being used.

A limitation of the study is that it would have been better to take contrast sensitivity into consideration. Moreover, subjective evaluation in the form of a questionnaire could have been used to further support the evidence.

In conclusion, patients with a high $\mathrm{SE}$ and large minimum pupil size ( $\mathrm{SE} \geq 4 \mathrm{~mm}$ ) suffered more disability glare than those with a low SE and small minimum pupil size.

Acknowledgements The authors thank Elizabeth Wadium for editing the manuscript.

Contributors Concept and design: FZ, TH, XC, XW, XZ. Data collection: FZ, TH, XC, ZC, KZ. Analysis and interpretation: FZ, TH, XC. Writing the article: FZ, TH, XC. Critical revision of the article: $Z C, K Z, X W, X Z$. Final approval of the article: all authors.

Funding Supported in part by the National Natural Science Foundation of China for Young Scholars (grant № 81600762 and 81500753), the National Natural Science Foundation of China (grant No 81570879 and 81770955) and the Project of Shanghai Science and Technology (grant No 17411950200 and 17411950201), the Shanghai Shenkang Hospital Development Center (grant No SHDC12016207) and the Health and Family Planning Committee of Pudong New District of Shanghai (grant No PW2014D-1).

Competing interests None declared.

Patient consent Obtained.

Ethics approval This study was approved by the ethics committee of the Eye and ENT Hospital of Fudan University.

Provenance and peer review Not commissioned; externally peer reviewed

Data sharing statement Available on request from the author TH.

Open Access This is an Open Access article distributed in accordance with the Creative Commons Attribution Non Commercial (CC BY-NC 4.0) license, which permits others to distribute, remix, adapt, build upon this work non-commercially, and license their derivative works on different terms, provided the original work is properly cited and the use is non-commercial. See: http://creativecommons.org/ licenses/by-nc/4.0/

(C) Article author(s) (or their employer(s) unless otherwise stated in the text of the article) 2018. All rights reserved. No commercial use is permitted unless otherwise expressly granted.

\section{REFERENCES}

1. Mainster MA, Turner PL. Glare's causes, consequences, and clinical challenges after a century of ophthalmic study. Am J Ophthalmol 2012;153:587-93.

2. Puell MC, Pérez-Carrasco MJ, Palomo-Alvarez C, et al. Relationship between halo size and forward light scatter. $\mathrm{Br} J$ Ophthalmol 2014;98:1389-92. 
3. Allen RJ, Saleh GM, Litwin AS, et al. Glare and halo with refractive correction. Clin Exp Optom 2008;91:156-60.

4. Palomo-Álvarez C, Puell MC. Capacity of straylight and disk halo size to diagnose cataract. J Cataract Refract Surg 2015;41:2069-74.

5. Cerviño A, Villa-Collar C, Gonzalez-Meijome JM, et al. Retinal straylight and light distortion phenomena in normal and post-LASIK eyes. Graefes Arch Clin Exp Ophthalmol 2011;249:1561-6.

6. Lackner B, Pieh S, Schmidinger G, et al. Glare and halo phenomena after laser in situ keratomileusis. $J$ Cataract Refract Surg 2003;29:444-50.

7. Chan A, Manche EE. Effect of preoperative pupil size on quality of vision after wavefront-guided LASIK. Ophthalmology 2011;118:736-41.

8. Patel SV, McLaren JW, Hodge DO, et al. The effect of corneal light scatter on vision after penetrating keratoplasty. Am J Ophthalmol 2008;146:913-9.

9. Pieh S, Lackner B, Hanselmayer G, et al. Halo size under distance and near conditions in refractive multifocal intraocular lenses. $\mathrm{Br} J$ Ophthalmol 2001;85:816-21.

10. Puell MC, Pérez-Carrasco MJ, Barrio A, et al. Normal values for the size of a halo produced by a glare source. $J$ Refract Surg 2013;29:618-22.

11. Martucci A, Cesareo M, Napoli D, et al. Evaluation of pupillary response to light in patients with glaucoma: a study using computerized pupillometry. Int Ophthalmol 2014;34:1241-7.
12. Münch M, Léon L, Crippa SV, et al. Circadian and wake-dependent effects on the pupil light reflex in response to narrow-bandwidth light pulses. Invest Ophthalmol Vis Sci 2012;53:4546-55.

13. Guillon M, Dumbleton K, Theodoratos $\mathrm{P}$, et al. The effects of age, refractive status, and luminance on pupil size. Optom Vis Sci 2016;93:1093-100.

14. Kadlecova V, Peleska M, Vasko A. Dependence on age of the diameter of the pupil in the dark. Nature 1958;182:1520-1.

15. Miao H, Tian M, He L, et al. Objective optical quality and intraocular scattering in myopic adults. Invest Ophthalmol Vis Sci 2014;55:5582-7.

16. Villa $C$, Gutiérrez R, Jiménez JR, et al. Night vision disturbances after successful LASIK surgery. Br J Ophthalmol 2007;91:1031-7.

17. Myung D, Schallhorn S, Manche EE. Pupil size and LASIK: a review. $J$ Refract Surg 2013;29:734-41.

18. Schallhorn S, Brown M, Venter J, et al. The role of the mesopic pupil on patient-reported outcomes in young patients with myopia 1 month after wavefront-guided LASIK. J Refract Surg 2014;30:159-65.

19. Haw WW, Manche EE. Effect of preoperative pupil measurements on glare, halos, and visual function after photoastigmatic refractive keratectomy. J Cataract Refract Surg 2001;27:907-16.

20. Pop M, Payette Y. Risk factors for night vision complaints after LASIK for myopia. Ophthalmology 2004;111:3-10.

21. Bailey MD, Mitchell GL, Dhaliwal DK, et al. Patient satisfaction and visual symptoms after laser in situ keratomileusis. Ophthalmology 2003;110:1371-8. 